\title{
Hydrogen sulfide treatment reduces blood pressure and oxidative stress in angiotensin II-induced hypertensive mice
}

\begin{abstract}
Mohammad R Al-Magableh ${ }^{1}$, Barbara K Kemp-Harper ${ }^{1}$ and Joanne L Hart ${ }^{2}$
Hydrogen sulfide $\left(\mathrm{H}_{2} \mathrm{~S}\right)$ is increasingly recognized as a gasotransmitter with protective effects in the cardiovascular system. The aim of the study was to examine the effects of chronic NaHS treatment on blood pressure, vascular function and oxidative stress in an in vivo model of hypertension and oxidative stress. Male C57BI6/J mice were rendered hypertensive with $0.7 \mathrm{mg} \mathrm{kg}^{-1}$ per day angiotensin II (AngII) for 14 days administered via implanted mini-pumps. The mice were treated with $\mathrm{NaHS}\left(10 \mu \mathrm{mol} \mathrm{kg}{ }^{-1}\right.$ per day) to deliver $\mathrm{H}_{2} \mathrm{~S}$ or an inhibitor of cystathionine- $\gamma$-lyase, DL-propargylglycine (PPG $30 \mathrm{mg} \mathrm{kg}^{-1} \mathrm{per}$ day) via intraperitoneal (i.p.) injection. Systolic blood pressure was measured and vascular function examined by myography. Vascular superoxide production was measured by lucigenin-enhanced chemiluminescence. Angll infusion significantly increased systolic blood pressure $(P<0.001)$. This increase was significantly attenuated by treatment with NaHS $(P<0.001)$. Both aortic endothelial function and NO bioavailability were significantly attenuated in the Angll group $(P<0.01)$ but this attenuation was reversed by NaHS treatment. Similarly, aortic superoxide anion production was significantly enhanced by Angll $(P<0.01)$, and this was reversed by NaHS treatment, and also exacerbated by PPG treatment $(P<0.001)$. These data show that in a mouse model of hypertension and oxidative stress induced by Angll, exogenous $\mathrm{H}_{2} \mathrm{~S}$ treatment in vivo reduces blood pressure, endothelial dysfunction and vascular oxidative stress, while inhibiting endogenous $\mathrm{H}_{2} \mathrm{~S}$ production in vivo is deleterious. This furthers the evidence that $\mathrm{H}_{2} \mathrm{~S}$ is a vasoprotective molecule that may be a useful treatment target in cardiovascular disease. Hypertension Research (2015) 38, 13-20; doi:10.1038/hr.2014.125; published online 7 August 2014
\end{abstract}

Keywords: NADPH oxidase; oxidative stress; superoxide; vasoprotection

\section{INTRODUCTION}

Hydrogen sulfide $\left(\mathrm{H}_{2} \mathrm{~S}\right)$ is a gasotransmitter ${ }^{1}$ reported to have numerous physiological effects in diverse processes including metabolism, inflammation, the nervous system and the cardiovascular system. The cardiovascular effects of this molecule are currently of major interest and include vascular relaxation, cardioprotective and vasculoprotective effects. ${ }^{2,3}$

In the cardiovascular system, $\mathrm{H}_{2} \mathrm{~S}$ is produced primarily by the pyridoxyl'5' phosphate-dependent enzyme cystathionine- $\gamma$-lyase (CSE, EC 4.4.1.1), which is present in both endothelial cells ${ }^{4}$ and vascular smooth muscle cells. ${ }^{5,6}$ Inhibition of CSE, with the irreversible inhibitor DL-propargylglycine (PPG), leads to an elevation of vascular tone in isolated aorta ${ }^{7}$ and an increase in blood pressure in vivo in rats. ${ }^{8}$ Most importantly, mice deficient in CSE display early endothelial dysfunction and hypertension. ${ }^{4} \mathrm{H}_{2} \mathrm{~S}$ is additionally reported to be produced by 3-mercaptopyruvate sulfurtransferase (EC 2.8.1.2) in concert with cysteine aminotransferase (EC 2.6.1.75) to metabolize cysteine. ${ }^{9}$
A key aspect of the biology of $\mathrm{H}_{2} \mathrm{~S}$ is its anti-oxidant effects. $\mathrm{H}_{2} \mathrm{~S}$ is a potent one-electron chemical reductant that is theoretically capable of scavenging free radicals by single electron or hydrogen atom transfer. ${ }^{10}$ Thus, $\mathrm{H}_{2} \mathrm{~S}$ may participate in many reactions ${ }^{11}$ and is reported to scavenge reactive oxygen and nitrogen species. ${ }^{11-16}$ However, the kinetics, reactivity and mechanism of $\mathrm{H}_{2} \mathrm{~S}$ interactions with reactive oxygen species (ROS) are poorly understood under physiological conditions. ${ }^{10}$ Further cytoprotective effects of NaHS have been attributed to its ability to decrease lipid peroxidation, ${ }^{12}$ increase glutathione levels and boost endogenous anti-oxidant defences. $^{17}$

Oxidative stress is an important feature in a number of cardiovascular disease states including hypertension, diabetes and atherosclerosis. $^{18,19}$ Blood vessels express NADPH oxidases; enzyme assemblies that contain catalytic 'NOX' subunits (or 'NOXs'), of which at least three isoforms, NOX1, NOX2 and NOX4, are responsible for the production of ROS in the vasculature. Both NADPH oxidase activity and expression are upregulated in

${ }^{1}$ Department of Pharmacology, Monash University, Clayton, Victoria, Australia and ${ }^{2}$ School of Medical Sciences, Health Innovations Research Institute, RMIT University, Bundoora, Victoria, Australia

Correspondence: Dr JL Hart, School of Medical Sciences, RMIT University, PO Box 71, Bundoora West, Victoria 3083, Australia.

E-mail: joanne.hart@rmit.edu.au

Received 6 May 2014; revised 16 June 2014; accepted 9 July 2015; published online 7 August 2014 
cardiovascular disease, with NOX2 playing a key role in the vascular dysfunction associated with these pathologies. ${ }^{20}$ Thus, strategies to limit oxidative stress in cardiovascular disease are sought and the antioxidant capacity of $\mathrm{H}_{2} \mathrm{~S}$ makes it an attractive candidate. It is well recognized that angiotensin II (AngII) can increase ROS generation in the vasculature, predominantly via activation of NOXs such as NOX2. Indeed, AngII-mediated NADPH oxidase activation and ROS production has been implicated in atherosclerosis and hypertension. ${ }^{21}$ As such, the AngII-infusion model of hypertension exploits the ability of AngII to increase NADPH oxidase activity ${ }^{22}$ and superoxide generation, and is useful as a model of both increased oxidative stress and hypertension. ${ }^{23}$

While to date there have been many in vitro studies examining the anti-oxidant effects of $\mathrm{H}_{2} \mathrm{~S}$, in vivo studies focusing on vascular effects are lacking, so the physiological relevance of such findings is yet to be fully explored. The aim of this study was to investigate whether or not exogenous $\mathrm{H}_{2} \mathrm{~S}$ can ameliorate vascular oxidative stress in vivo and thereby confer vasoprotection, using the AngII-induced oxidative stress and hypertension model in mice. These studies are an important next step from the in vitro evidence of $\mathrm{H}_{2} \mathrm{~S}$ as an antioxidant ${ }^{16}$ to proving its capacity as a vasoprotectant in vivo.

\section{MATERIALS AND METHODS}

\section{Animals}

All experimental procedures involving the use of animals were approved by the RMIT Animal Ethics Committee before the commencement of this project. This investigation conforms to the Guide for the Care and Use of Laboratory Animals published by the US National Institutes of Health (NIH Publication No. 85-23 revised 1996). All animals were housed in the RMIT Animal Facility, RMIT University, Bundoora West Campus on a 12-h day/night cycle at room temperature of $20 \pm 2{ }^{\circ} \mathrm{C}$. Male C57BL/6J mice, 10 weeks of age were purchased from the Animal Resource Centre, Western Australia.

\section{Angiotensin II-induced hypertension}

Mice (C57Bl6/J, male 10 weeks) were anesthetized with $2 \%$ isoflurane in oxygen, and an osmotic mini-pump (Alzet micro-osmotic pump model 1004; Alzet DURECT Corporation, Cupertino, CA, USA) was implanted subcutaneously between the scapulae. Mice were infused for 2 weeks with angiotensin II (AngII) $0.7 \mathrm{mg} \mathrm{kg}^{-1}$ per day, prepared in AngII buffer (composition: $3 \mathrm{ml}$ of

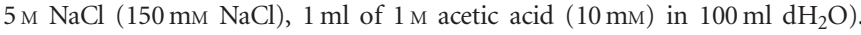
The animals were divided into four groups; (1) no treatment, (2) AngIl infusion, (3) AngII infusion and PPG $3 \mathrm{mg} \mathrm{kg}^{-1}$ per day i.p., (4) AngII infusion and NaHS $10 \mu \mathrm{mol} \mathrm{kg}^{-1}$ per day, i.p.

\section{Blood pressure measurement}

The systolic blood pressure of the animals was measured 1 day before the insertion of the mini-pumps and 7 and 14 days after the procedure, using the non-invasive tail cuff apparatus (ADInstruments, Sydney, NSW, Australia). Systolic blood pressure was averaged from four to six consecutive measurements taken at intervals of 1-2 min. After measurement of systolic blood pressure on day 14 , mice were culled in a humane manner via $\mathrm{CO}_{2}$ asphyxiation $\left(95 \% \mathrm{CO}_{2}, 5 \% \mathrm{O}_{2}\right)$, followed by cervical dislocation and decapitation. The aorta was dissected out and washed in ice-cold oxygenated Krebs' solution (composition in mM: $\mathrm{NaCl} 119, \mathrm{KCl} 4.7, \mathrm{MgSO}_{4} 1.17, \mathrm{NaHCO}_{3}$ 25, $\mathrm{KH}_{2} \mathrm{PO}_{4} 1.18, \mathrm{CaCl}_{2}$ 2.5, glucose 5.5, EDTA 0.026, pH 7.4).

\section{Myograph experiments}

Abdominal aortic rings ( $\sim 2 \mathrm{~mm}$ length) were mounted in $7 \mathrm{ml}$ myograph chambers, where they were maintained in Krebs' solution at $37^{\circ} \mathrm{C}$, continuously supplied with carbogen $\left(95 \% \mathrm{O}_{2}, 5 \% \mathrm{CO}_{2}\right)$. Changes in isometric force were recorded using Myograph Interface model 610M (ADInstruments) and the Myodac data acquisition system (Myodac 2.01, Myonic Software, Copenhagen, Denmark). The aortic rings were allowed to equilibrate for $20 \mathrm{~min}$ under zero force then a $5-\mathrm{mN}$ resting tension was applied. Following a 15-min equilibration period at $5 \mathrm{mN}$, the aortic rings were maximally contracted using the thromboxane $\mathrm{A}_{2}$ mimetic, $\mathrm{U} 466191 \mu \mathrm{M}\left(\mathrm{U} 4_{\max }\right)$. The aortic rings were washed with Krebs' solution and the tension allowed to return to baseline Concentration response curves to the endothelium-dependent dilator acetylcholine (ACh $1 \mathrm{~nm}-10 \mu \mathrm{M}$ ), the NO donor sodium nitroprusside (SNP $0.1 \mathrm{nM}-10 \mu \mathrm{M}$ ), the $\mathrm{K}_{\mathrm{ATP}}$ channel opener levcromakalim (LKM $1 \mathrm{nM}-10 \mu \mathrm{M}$ ), NaHS $(1 \mu \mathrm{M}-3 \mathrm{~mm})$ or the CSE substrate L-cysteine $(10 \mu \mathrm{M}-3 \mathrm{~mm})$ were constructed in vessels pre-constricted with the thromboxane analogue U46619. Pre-contraction to U46619 was submaximal ( 50\% U4 $\left.4_{\max }\right)$ and not significantly different between groups. At the end of each concentration response curve, $10 \mu \mathrm{m}$ nifedipine was added to test vascular smooth muscle cell function. In the NO bioavailability experiments, the vessels were contracted to $20-30 \%$ of $\mathrm{U} 44_{\max }$ using titrated concentration of U46619, and after the contraction stabilized $(\sim 10 \mathrm{~min})$, L-NAME $100 \mu \mathrm{m}$ was added. After the contraction to L-NAME stabilized for $30 \mathrm{~min}$, the contraction value was taken and compared with $\mathrm{U} 4_{\max }$.

\section{Superoxide production from vascular tissue}

$\mathrm{NADPH}$ oxidase-driven superoxide production in abdominal aorta was measured using lucigenin-enhanced chemiluminescence. Sections of abdominal aorta $\left(3 \mathrm{~mm}\right.$ long) were pre-incubated for $45 \mathrm{~min}$ at $37^{\circ} \mathrm{C}$ in KrebsHEPES buffer (composition (mM): $\mathrm{NaCl}$ 99.9, $\mathrm{KCl}$ 4.7, $\mathrm{KH}_{2} \mathrm{PO}_{4} \quad 1.0$, $\mathrm{MgSO}_{4} \cdot 7 \mathrm{H}_{2} \mathrm{O}$ 1.2, D-glucose 11.0, $\mathrm{NaHCO}_{3} 25.0, \mathrm{CaCl}_{2} \cdot 2 \mathrm{H}_{2} \mathrm{O}$ 2.5, Na HEPES $20.0, \mathrm{pH}$ 7.4) containing diethylthiocarbamic acid (1 mM) to inactivate superoxide dismutase, and NADPH $(100 \mu \mathrm{M})$ as a substrate for NADPH oxidase. Diphenylene iodonium $(1 \mu \mathrm{M})$ was used to inhibit NADPH oxidase in some wells. In all, $300 \mu \mathrm{l}$ of Krebs-HEPES buffer containing lucigenin $(5 \mu \mathrm{M})$ was placed in separate wells of a white 96-well Opti-plate which was loaded into a Polarstar Optima photon counter (BMG Labtech, Melbourne, VIC, Australia) to measure background photon emission at $37^{\circ} \mathrm{C}$ over a $30-\mathrm{min}$ period. After background counting was completed, a single ring of aorta was added to each well, in semi-darkness, and photon emission was measured for $30 \mathrm{~min}$. Superoxide production for each ring segment was calculated by subtracting the background chemiluminescence signal from the signal in the presence of the artery $\left(10^{3}\right.$ counts per second) and then normalized to dry tissue weight (in $\mathrm{mg}$ ).

\section{CSE activity assay}

The $\mathrm{H}_{2} \mathrm{~S}$ production rate in various tissues was measured as described previously ${ }^{24}$ with modifications. In brief, tissues were collected from mice, weighed and homogenized in ice-cold potassium phosphate buffer, $\mathrm{pH}$ 7.4. The reaction mixture contained $100 \mathrm{~mm}$ potassium phosphate buffer, $\mathrm{pH} 7.4,10 \mathrm{~mm}$ L-cysteine, $2 \mathrm{~mm}$ pyridoxyl'5'phosphate and $10 \%(\mathrm{w} / \mathrm{v})$ tissue homogenates. Cryovial test tubes $(2 \mathrm{ml})$ were used to trap $\mathrm{H}_{2} \mathrm{~S}$, each containing $0.5 \mathrm{ml} 1 \%$ zinc acetate and a filter paper of $4 \mathrm{~cm}^{2}$ to increase the air/fluid surface area. The reaction was performed in $50 \mathrm{ml}$ falcon tubes, each falcon tube contained a trapping solution and a reaction mixture tube, and it was sealed by a double layer of parafilm. The reaction was initiated by transferring the tubes into a $37^{\circ} \mathrm{C}$ shaking water bath. After incubation for $90 \mathrm{~min}$, the tubes were put on ice for another $30 \mathrm{~min}$ to stop the reaction and to ensure complete trapping of $\mathrm{H}_{2} \mathrm{~S}$. The contents of the trapping tube were transferred into test tubes each

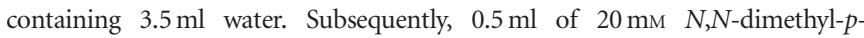
phenylenediamine sulfate prepared in $7.2 \mathrm{M} \mathrm{HCl}$ was added followed by $0.4 \mathrm{ml}$ of $30 \mathrm{mM} \mathrm{FeCl}_{3}$ prepared in $1.2 \mathrm{M} \mathrm{HCl}$. The absorbance of the resulting solution was measured at $670 \mathrm{~nm}$ after $20 \mathrm{~min}$ with a spectrophotometer. The $\mathrm{H}_{2} \mathrm{~S}$ produced from the reaction was calculated from a calibration curve of standard $\mathrm{H}_{2} \mathrm{~S}$ solution prepared by dissolving $\mathrm{Na}_{2} \mathrm{~S}$ in deoxygenated water under anoxic conditions. A single calibration curve was used to calculate $\mathrm{H}_{2} \mathrm{~S}$ concentration from each experiment. $\mathrm{H}_{2} \mathrm{~S}$ production was normalized to the wet tissue weight and expressed as $\mu \mathrm{molg}^{-1}$ per minute.

\section{Data analysis and statistics}

Results are expressed as mean \pm standard error of the mean (s.e.m.) with the number of experiments denoted by $n$. Concentration response curves to ACh were expressed as a percentage reversal of the U46619 pre-contraction. These data were computer fitted to a sigmoidal curve using non-linear regression 


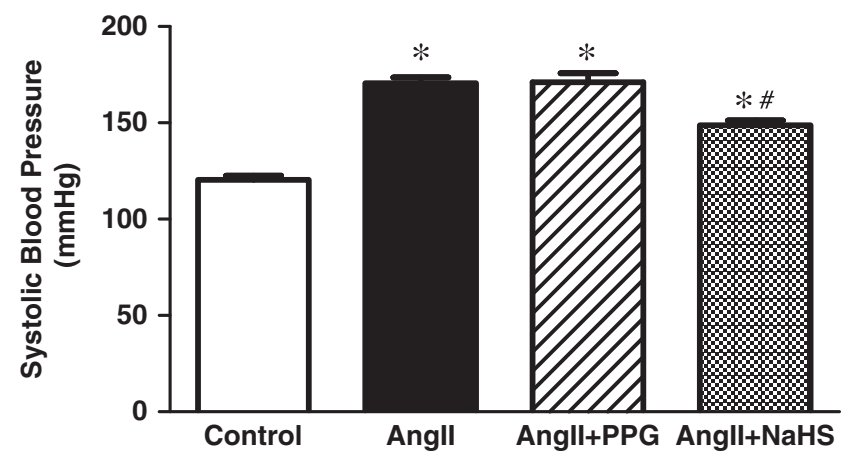

Figure 1 Effect of $\mathrm{NaHS}\left(10 \mu \mathrm{mol} \mathrm{kg}{ }^{-1}\right.$ per day) and the CSE inhibitor PPG ( $3 \mathrm{mg} \mathrm{kg}^{-1}$ per day) on the Angll $\left(0.7 \mathrm{mg} \mathrm{kg}^{-1}\right.$ per day)-induced increase in systolic blood pressure in $\mathrm{C} 57 \mathrm{~B} / 6 / \mathrm{J}$ mice. Systolic blood pressure was measured on day 14 after commencing the Angll infusion. ${ }^{*} P<0.001$ vs. Control, ${ }^{*} P<0.001$ vs. Angll, one-way ANOVA, post hoc Dunnett's test, $n=10-12$.

(Graphpad Prism 5, Graphpad Software Inc, La Jolla, CA, USA) to provide an estimate of the concentration of agonist causing a $50 \%$ relaxation $\left(\mathrm{pEC}_{50}\right.$ value; in $-\log \mathrm{moll}^{-1}$ ). Statistical analysis was performed using either unpaired $t$-tests or by one-way analysis of variance (ANOVA) with post hoc tests applied as appropriate and as stated in the text (GraphPad Prism, Version 5). $P<0.05$ was considered as statistically significant.

\section{Drugs and reagents}

All drugs and reagents were purchased from Sigma-Aldrich (St Louis, MO, USA). All drugs were dissolved in $\mathrm{dH}_{2} \mathrm{O}$, with the exception of LKM, which was dissolved in methanol.

\section{RESULTS}

Effect of AngII infusion on systolic blood pressure

There was no difference in the systolic blood pressure between the experimental groups at the commencement of the study (data not shown). AngII infusion $\left(0.7 \mathrm{mg} \mathrm{kg}^{-1}\right.$ per day) for 14 days caused a significant increase in systolic blood pressure (Control $120 \pm 2$ vs. AngII $171 \pm 3 \mathrm{~mm} \mathrm{Hg}, P<0.001)$. Concomitant treatment with $\mathrm{NaHS}$ $\left(10 \mu \mathrm{mol} \mathrm{kg}^{-1}\right.$ per day, i.p.) significantly attenuated this rise in systolic blood pressure $(P<0.001)$; however, treatment with the CSE inhibitor PPG ( $3 \mathrm{mg} \mathrm{kg}^{-1}$ per day, i.p.) had no effect on the AngII-induced increase in systolic blood pressure (Figure 1).

Vascular responses in aorta from AngII-infused mice

Effect of AngII infusion on endothelial function. In aortic rings the vasorelaxant response to the endothelium-dependent vasodilator ACh was significantly reduced in the AngII and the AngII + PPG-treated groups compared with the control group $(P<0.001)$. Combining AngII + NaHS reversed this endothelial dysfunction $(P<0.001$, Figure 2a, Table 1).

Effect of AngII infusion on endogenous nitric oxide bioavailability. The contraction response to L-NAME $(100 \mu \mathrm{M})$ was significantly reduced in the AngII and the AngII + PPG-treated groups compared with that of the control group $(P<0.001)$, indicative of decreased endogenous NO bioavailability. Combining AngII + NaHS restored the response to L-NAME to a level comparable to that of the control $(P<0.001$, Figure $2 \mathrm{~b}$, Table 1).

Effects of AngII infusion on vascular smooth muscle function. The sensitivity to the vasorelaxant response to the NO donor SNP was significantly reduced in the AngII and the AngII + PPG-treated

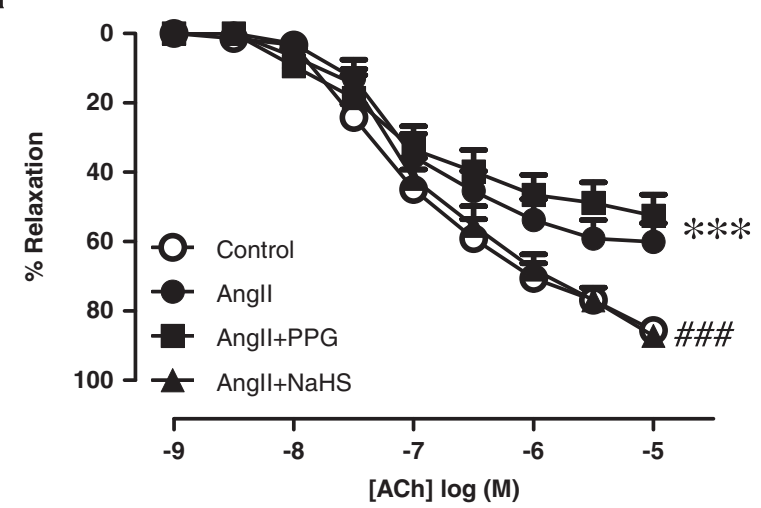

b

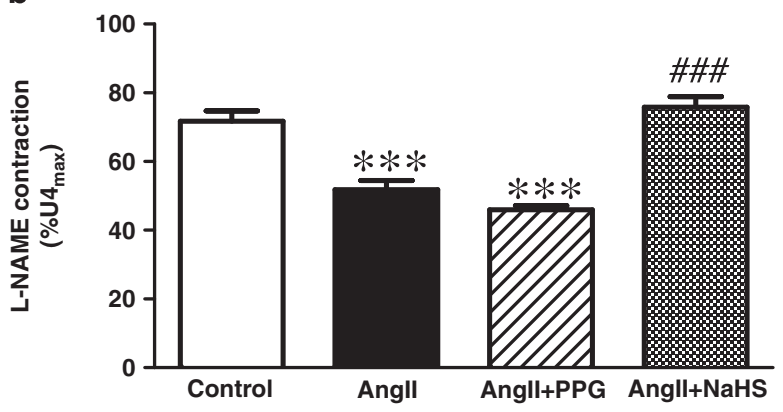

Figure 2 (a) Concentration response curves to the endothelium-dependent vasodilator acetylcholine (ACh), in aorta from mice chronically infused with Angll for 14 days and treated with either NaHS or the CSE inhibitor PPG. $\bigcirc$ Control, - Angll, $\Delta$ Angll $+\mathrm{NaHS}$ and Angll + PPG. Response is expressed as \% reversal of the pre-contraction to U46619. ${ }^{* * *} P<0.001$ max relaxation vs. control, \#\# $P<0.001$ max relaxation vs. Angll, one-way ANOVA, post hoc Dunnett's test, $n=8-10$. (b) Endogenous vascular nitric oxide bioavailability determined by the contraction response to L-NAME $(100 \mu \mathrm{m})$ in aortic rings from mice chronically infused with Angll for 14 days and treated with either the CSE inhibitor PPG or NaHS. The contraction response to L-NAME is presented as percentage of the maximum contraction to U46619 $1 \mu \mathrm{m} .{ }^{* * *} P<0.001$, vs. control, \#\#\# $P<0.001$ vs. AnglI, one-way ANOVA, post hoc Dunnett's test, $n=4$.

groups compared with that of the control $(P<0.05)$. However, the maximal relaxation response was unaffected. Combining AngII + NaHS restored the sensitivity to SNP back to the level of the control (Figure 3a). The vasorelaxant response to the $\mathrm{K}_{\mathrm{ATP}}$ channel opener LKM was not different across the treatment groups (Figure $3 \mathrm{~b}$, Table 1).

Effect of AngII infusion treatment on NADPH-dependent vascular superoxide production. Chronic angiotensin infusion (14 days) in mice lead to a significant increase in NADPH-dependent superoxide generation in isolated aortae $(P<0.01)$, an effect that was further augmented by combining AngII + PPG $(P<0.001)$. Combining AngII + NaHS significantly reduced superoxide production in the aorta of these mice, back to the levels seen in the control group $(P<0.01$, Figure 4).

Effect of AngII infusion on vascular CSE activity. In aorta the vasorelaxation response to NaHS was unaffected by AngII infusion, or any of the treatments (PPG or NaHS) indicating no change in the ability of the vessels to respond to exogenous $\mathrm{H}_{2} \mathrm{~S}$ (Figure 5a). Maximum vasorelaxation induced by the CSE substrate, L-cysteine was significantly inhibited in the PPG-treated group $(P<0.01)$ and slightly inhibited by AngII infusion alone, indicative of a reduction in 
Table 1 Supplementary data for myograph experiments

\begin{tabular}{lccccc}
\hline Treatment & $\mathrm{F}_{\max }$ & $\mathrm{n}$ & $\%$ Pre-contraction & $p E C_{50}$ & Max relaxation \\
\hline ACh response & & & & & \\
$\quad$ Control & $19 \pm 1$ & 8 & $59 \pm 3$ & $7.01 \pm 0.07$ & $82 \pm 3$ \\
AngII & $18 \pm 1$ & 9 & $65 \pm 2$ & $7.07 \pm 0.10$ & $59 \pm 3^{* * *}$ \\
AngII + NaHS & $15 \pm 1$ & 5 & $58 \pm 3$ & $6.84 \pm 0.09$ & $85 \pm 4$ \\
AngII + PPG & $15 \pm 1$ & 10 & $62 \pm 3$ & $7.24 \pm 0.16$ & $51 \pm 4^{* * *}$ \\
& & & & & \\
SNP response & & & & & \\
Control & $17 \pm 1$ & 8 & $52 \pm 6$ & $7.86 \pm 0.06$ & $94 \pm 2$ \\
AngII & $17 \pm 2$ & 8 & $50 \pm 5$ & $7.35 \pm 0.09 \phi$ & $95 \pm 4$ \\
AngII + NaHS & $16 \pm 2$ & 7 & $54 \pm 5$ & $7.25 \pm 0.03$ & $93 \pm 1$ \\
AngII + PPG & $17 \pm 2$ & 9 & $55 \pm 6$ & $7.72 \pm 0.08$ & $94 \pm 3$ \\
& & & & & \\
LKM response & & & & & \\
Control & $19 \pm 3$ & 4 & $62 \pm 3$ & $7.686 \pm 0.07$ & $71 \pm 2$ \\
AngII & $20 \pm 2$ & 4 & $51 \pm 3$ & $7.541 \pm 0.05$ & $68 \pm 2$ \\
AngII+ NaHS & $18 \pm 2$ & 4 & $60 \pm 2$ & $7.525 \pm 0.05$ & $69 \pm 2$ \\
AngII + PPG & $19 \pm 3$ & 4 & $62 \pm 3$ & $7.658 \pm 0.11$ & $66 \pm 4$ \\
& & & & & \\
L-NAME response & & & & & - \\
Control & $19 \pm 3$ & 4 & $35 \pm 1$ & - & - \\
AngII & $24 \pm 2$ & 4 & $29 \pm 2$ & - & - \\
AngII + NaHS & $18 \pm 2$ & 4 & $33 \pm 4$ & - & - \\
AngII + PPG & $14 \pm 2$ & 4 & $38 \pm 2$ & - & - \\
\hline
\end{tabular}

Abbreviations: ACh, acetylcholine; AngII, angiotensin II; LKM, levcromakalim; PPG, DL-propargylglycine; SNP, sodium nitroprusside.

Values are presented as mean \pm s.e.m. $F_{\max }$ (Maximum contraction to U46619), Pre-contraction

$\left(\% F_{\max }\right)$.
$* * * P<0.001$ cf control, one-way ANOVA.

$* * *$
$\phi P<0.05$

endogenous $\mathrm{H}_{2} \mathrm{~S}$ generation. Treatment with NaHS reversed the inhibitory effect of Ang II infusion on L-cysteine mediated vasorelaxation (Figure 5b). In addition, $\mathrm{H}_{2} \mathrm{~S}$ production in aorta from AngII-infused mice was virtually abolished by PPG treatment $(P<0.001)$ and significantly attenuated in the AngII-treated group compared with the control $(P<0.05)$. Treatment with NaHS restored aortic $\mathrm{H}_{2} \mathrm{~S}$ production back to the levels of the control $(P<0.05$, Figure 5c).

\section{DISCUSSION}

This study presents data that highlight the potential importance of $\mathrm{H}_{2} \mathrm{~S}$ as a vasoprotectant molecule. Chronic AngII infusion in mice for 14 days caused hypertension, increased vascular superoxide production, endothelial dysfunction, reduction in endogenous NO bioavailability, and a decrease in NO signalling and endogenous $\mathrm{H}_{2} \mathrm{~S}$ production via CSE. All these effects were reversed by supplying exogenous $\mathrm{H}_{2} \mathrm{~S}$. The increase in vascular superoxide production and a decrease in endogenous $\mathrm{H}_{2} \mathrm{~S}$ production were exacerbated by inhibition of the endogenous $\mathrm{H}_{2} \mathrm{~S}$ producing enzyme CSE. This study supports previous reports of the anti-oxidant, ${ }^{16,25}$ cardioprotective, ${ }^{26}$ and cytoprotective $e^{27,28}$ effects of $\mathrm{H}_{2} \mathrm{~S}$ and extends the repertoire of $\mathrm{H}_{2} \mathrm{~S}$ to specifically include vasoprotectant actions in vivo.

AngII infusion caused a marked increase in systolic blood pressure that was reduced by NaHS. NaHS is a known vasorelaxant with effects in both conduit arteries ${ }^{7,29}$ and resistance-like vessels. ${ }^{30-32}$ The molecular mechanism of vasorelaxation induced by $\mathrm{H}_{2} \mathrm{~S}$ is controversial, with roles for $\mathrm{K}^{+}$channels, $\mathrm{Ca}^{2+}$ channels and $\mathrm{Cl}^{-}$ channels all being implicated. More recently, it has been reported that $\mathrm{H}_{2} \mathrm{~S}$ is a phosphodiesterase inhibitor and cGMP-dependent protein
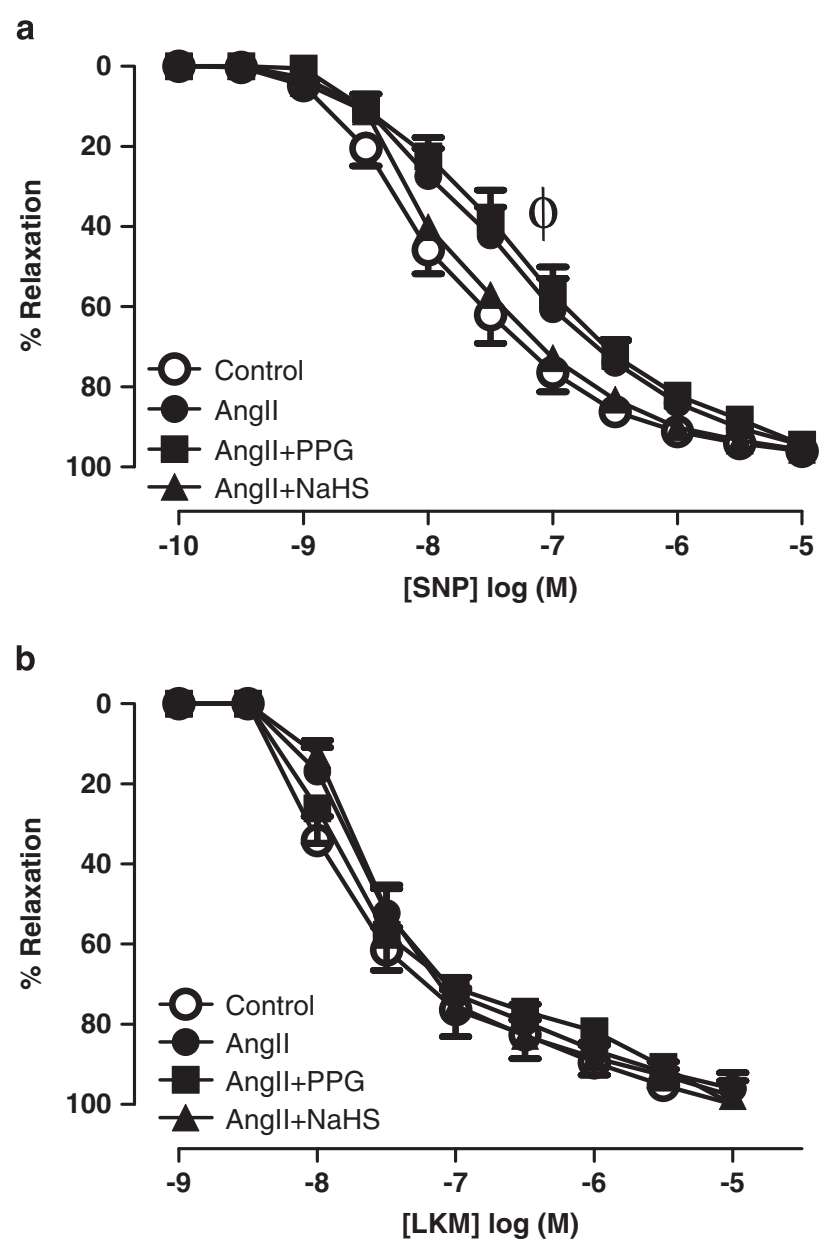

Figure 3 Concentration response curves to the (a) NO donor SNP and (b) $\mathrm{K}_{\text {ATP }}$ channel opener LKM in aorta from mice chronically infused with Angll for 14 days and treated with either the CSE inhibitor PPG or NaHS. 0 Control, Angll, $\boldsymbol{\Delta}$ Angll $+\mathrm{NaHS}$ and Angll + PPG. Responses are expressed as \% reversal of the pre-contraction to U46619. $\Phi=P<0.05$ $\mathrm{EC}_{50}$, vs. control, ANOVA, post hoc Dunnett's test, $n=5-9$.

kinase (PKG-I) activator ${ }^{33,34}$ and that vasorelaxation is reliant on underlying cGMP production. While the mechanism(s) via which $\mathrm{H}_{2} \mathrm{~S}$ donors elicit vasorelaxation remain to be fully elucidated it is well recognized that $\mathrm{H}_{2} \mathrm{~S}$ donors are effective vasodilators both in vitro and also in vivo. Indeed, intravenous administration of $\mathrm{NaHS}^{8}$ or the $\mathrm{H}_{2} \mathrm{~S}$ donor compound GYY $4137^{35}$ have been shown to reduce blood pressure in vivo. It is most likely that the vasorelaxant actions of $\mathrm{H}_{2} \mathrm{~S}$ contribute to the NaHS-induced antihypertensive effect observed in the current study, but this is possibly not the only reason NaHS reduces blood pressure in the AngII-infusion model of hypertension. AngII activates $\mathrm{AT}_{1}$ receptors $\left(\mathrm{AT}_{1} \mathrm{Rs}\right)$ to cause vasoconstriction and signals by markedly increasing vascular NADPH oxidase activity. ${ }^{36}$ The increased superoxide production will lead to a reduction in NO bioavailability, which in turn leads to increased vascular tone, ${ }^{21,36}$ thus a reduction in superoxide levels by $\mathrm{H}_{2} \mathrm{~S}$ could also impede the development of increased vascular tone to AngII.

Another possible mechanism of the protective effects seen by NaHS in this study is an interaction with the $\mathrm{AT}_{1} \mathrm{R}$ itself. It is well known that the $\mathrm{AT}_{1} \mathrm{R}$ has two extracellular disulfide bonds that are important for AngII binding. When these disulfide bonds are reduced by thiolreducing agents (for example, dithiothreitol ${ }^{37}$ or $\mathrm{N}$-acetylcysteine ${ }^{38}$ in 


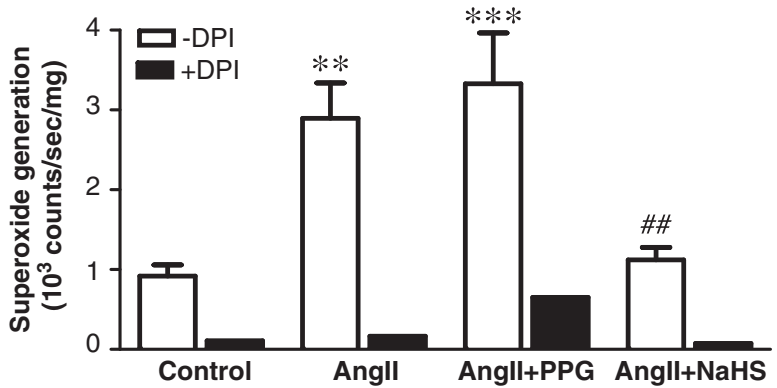

Figure 4 NADPH $\left(100 \mu \mathrm{moll}^{-1}\right)$-stimulated superoxide levels in mouse aortic rings, after 14 days infusion with Angll $\left(0.7 \mathrm{mg} \mathrm{kg}^{-1}\right.$ per day) with additional treatment with either the CSE inhibitor PPG $\left(3 \mathrm{mg} \mathrm{kg}^{-1}\right.$ per day) or $\mathrm{NaHS}\left(10 \mu \mathrm{mol} / \mathrm{kg}^{-1}\right.$ per day). Superoxide was measured by lucigenin $\left(5 \mu \mathrm{moll} \mathrm{I}^{-1}\right)$-enhanced chemiluminescence in the absence (open bars) and presence (closed bars) of the NADPH oxidase inhibitor diphenylene iodonium (DPI) $\left(1 \mu \mathrm{moll} \mathrm{I}^{-1}\right)$. Values are expressed as $10^{3}$ counts per second per milligram of dry tissue. ${ }^{* *} P<0.01,{ }^{* * *} P<0.001$, vs. control, ${ }^{\#} P<0.01$ vs. Angll; one-way ANOVA, post hoc Dunnett's test, $n=9-13$.

cellular binding assays, AngII binding to the $\mathrm{AT}_{1} \mathrm{R}$ is inhibited. Similarly, dithiothreitol reduces the vasocontraction response to AngII in in vitro vascular assays ${ }^{39}$ thus it is established that reducing agents can decrease AngII binding to the $\mathrm{AT}_{1} \mathrm{R}$ and block downstream signalling events. Interestingly, $\mathrm{AT}_{2}$ receptor-mediated effects are enhanced by dithiothreitol. ${ }^{40} \mathrm{H}_{2} \mathrm{~S}$ is a known thiol reducing agent and there is evidence that it too can inhibit AngII-mediated signalling. ${ }^{41}$ Thus, a possible mechanism in this study is that NaHS is causing an inhibition of AngII binding to $\mathrm{AT}_{1} \mathrm{R}$, ameliorating AngII-mediated signalling and inhibiting the progression of the pathology of the model and furthermore NaHS may be enhancing $\mathrm{AT}_{2}$ receptor-mediated effects (vasodilatation and anti-proliferative effects) that counteract the effects of the $\mathrm{AT}_{1} \mathrm{R}^{42}$

NaHS treatment inhibited NADPH-dependent superoxide production in aorta ex vivo as assessed by lucigenin-enhanced chemiluminescence. It has previously been shown that $\mathrm{H}_{2} \mathrm{~S}$ can inhibit NADPH oxidase in cell-based studies, where it inhibits NOX1 expression and Racl activity in vascular smooth muscle cells ${ }^{43}$ and gp91phox expression in endothelial cells. ${ }^{44}$ Additionally, recent in vitro studies have shown an anti-oxidant and vasoprotective effect of NaHS. ${ }^{16}$ This is the first report to show that chronic treatment with an $\mathrm{H}_{2} \mathrm{~S}$ donor can affect superoxide production in vivo in a hypertension model. Previous work has shown a similar effect in an atherosclerosis model ${ }^{45}$ suggesting a role for $\mathrm{H}_{2} \mathrm{~S}$ as a vascular antioxidant. In addition, $\mathrm{H}_{2} \mathrm{~S}$ has been reported to act as a scavenger for a variety of ROS, including superoxide, ${ }^{16,46,47}$ hydrogen peroxide, ${ }^{43}$ peroxynitrite ${ }^{12,13}$ and hypochloride. ${ }^{15}$ Thus, $\mathrm{H}_{2} \mathrm{~S}$ may both inhibit vascular ROS production and act as a scavenger of ROS, increasing its anti-oxidant potential.

Endothelium-derived NO is destroyed by oxidative stress as NO and superoxide rapidly react to form peroxynitrite. ${ }^{48,49}$ The detrimental outcomes of this reaction are twofold. First, the beneficial vascular actions of $\mathrm{NO}$ are impaired and second peroxynitrite is a highly reactive molecule which can cause protein nitration and lipid peroxidation. ${ }^{50}$ Further, peroxynitrite causes single-strand DNA breakage and it oxidizes tetrahydrobiopterin, an important endogenous nitric oxide (eNOS) co-factor. Depletion of tetrahydrobiopterin is one trigger for the uncoupling of eNOS which then produces superoxide instead of $\mathrm{NO}^{51}$ adding to the oxidant load. This increased oxidative stress is an important factor in the development of hypertension. ${ }^{52}$ An important finding of this
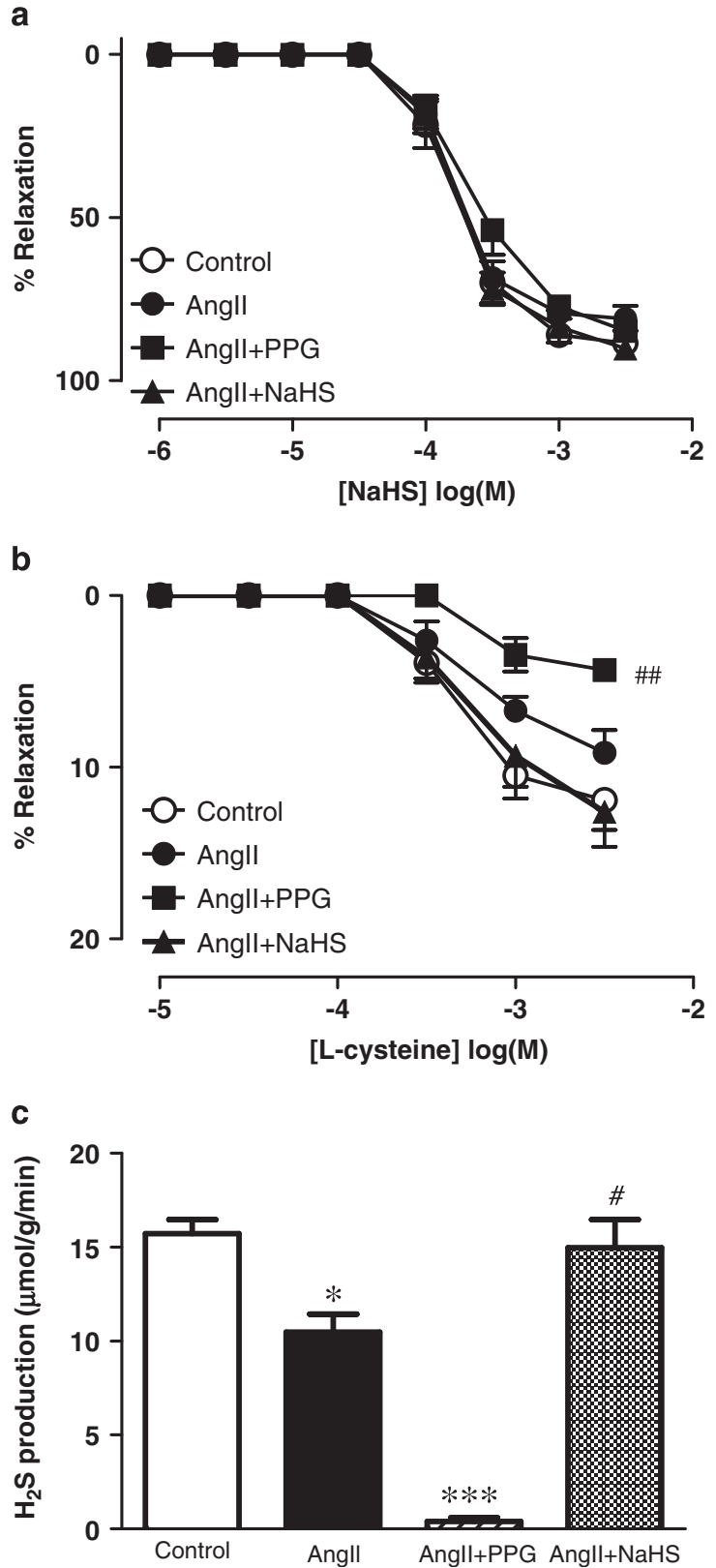

Figure 5 Concentration response curves in aorta from mice chronically infused with Angll for 14 days and treated with either the CSE inhibitor PPG or NaHS, $n=4-6$. O Control, - Angll, A AngII+NaHS and AngII+PPG. (a) The vasorelaxation response to exogenous $\mathrm{H}_{2} \mathrm{~S}$ via $\mathrm{NaHS}$, (b) the vasorelaxation response to the CSE substrate L-cysteine, $\# \# P 0.01$ maximum relaxation vs. control, one-way ANOVA, $n=5$. (c) Aortic $\mathrm{H}_{2} \mathrm{~S}$ production assessed by the methylene blue assay ${ }^{*} P<0.05$, ${ }^{* * *} P<0.001$, vs. control, ${ }^{\prime} P<0.05$ vs. Angll, one-way ANOVA, post hoc Dunnett's test, $n=4$.

study is that NaHS treatment prevented endothelial dysfunction caused by AngII infusion. The endothelial dysfunction in this model is known to be due to increased superoxide production since it is reversed by scavengers of ROS and exacerbated by the deficiency of key endogenous anti-oxidants. ${ }^{53,54}$ The endothelial impairment shown in this study is likely to be due to a reduction in NO bioavailability. NO bioavailability was assessed in this study by examining the contractile response to L-NAME, an inhibitor of eNOS. These experiments reflect the availability of endogenous NO 
release which is controlling basal tone. ${ }^{55}$ The contractile response to L-NAME was significantly impaired in the AngII-treated group whereas the response in the NaHS-treated group was comparable to that of the control. These data confirm that NO bioavailability is impaired under oxidative stress, and that NaHS treatment can reverse this impairment. Thus, the ability of $\mathrm{H}_{2} \mathrm{~S}$ to inhibit NADPH oxidasederived superoxide would protect the vasculature from peroxynitritemediated damage. Additionally, $\mathrm{H}_{2} \mathrm{~S}$ donors have been shown to elevate glutathione levels, ${ }^{17}$ increase the activity of glutathione peroxidase and glutathione reductase, ${ }^{56}$ increase the activity and expression of superoxide dismutase, ${ }^{57,58}$ and increase eNOS phosphorylation $^{59}$ and activity ${ }^{60}$ and expression ${ }^{61}$ implying $\mathrm{H}_{2} \mathrm{~S}$ has the capacity for a multi-faceted enhancement of anti-oxidant mechanisms and the protection of endogenous NO.

In addition to the impaired endogenous NO bioavailability in the AngII-infusion model, there was also impairment in the response to the NO donor SNP. The vasorelaxation response to the $\mathrm{K}_{\mathrm{ATP}}$ channel opener LKM was the same in all groups, indicating that vascular smooth muscle cell vasorelaxant function per se was not affected; thus, the attenuation of SNP-induced relaxation indicates a problem in downstream NO signalling, rather than damage to the vascular smooth muscle. While maximal relaxation was preserved, the $\mathrm{EC}_{50}$ for SNP was significantly shifted to the right in the AngII-infused animals, compared with the control and the NaHS-treated group. This may suggest that the superoxide production of the aorta was sufficient to scavenge exogenously generated NO, or interfere with downstream NO signalling. Treatment with NaHS restored the sensitivity to the NO donor. There are a number of possible explanations for this effect. It may be that $\mathrm{H}_{2} \mathrm{~S}$ is promoting cGMP-mediated signalling by inhibiting phosphodiesterase. ${ }^{33}$ Additionally, the activity and expression of the sGC can be directly impaired by oxidative stress due to oxidation of its ferrous heme which prevents NO-mediated activation of sGC. ${ }^{62}$ As a scavenger of ROS and a chemical reductant, NaHS may also be acting to protect the ferric form of sGC and therefore preserving the receptor for NO in the vascular smooth muscle cell, providing a further explanation for the improvement of both endothelial function and sensitivity to SNP in the NaHS-treated group.

PPG is a widely used inhibitor of CSE, which acts by irreversibly binding to the pyridoxyl-5-phosphate binding site. ${ }^{63}$ Despite quite poor cell permeability PPG does exhibit selectivity in inhibiting CSE $^{64}$ and is a well-used pharmacological tool in this field. On the basis of using PPG as an inhibitor of CSE, at the same concentrations, previous studies have shown that endogenous $\mathrm{H}_{2} \mathrm{~S}$ is involved in the regulation of basal blood vessel tone ${ }^{7}$ and indeed blood pressure. ${ }^{8}$ In this study, treatment with the CSE inhibitor PPG did not further increase blood pressure, or endothelial dysfunction, but did increase superoxide production and reduce vascular CSE activity. That inhibiting endogenous $\mathrm{H}_{2} \mathrm{~S}$ production causes little further exacerbation of the deleterious effects of AngII infusion is not unexpected. A simple explanation for this is that endogenous $\mathrm{H}_{2} \mathrm{~S}$ is not sufficient to ameliorate the hemodynamic and vascular changes induced by AngII. In addition, the $\mathrm{H}_{2} \mathrm{~S}$ production data suggest that AngII infusion leads to a decrease in endogenous $\mathrm{H}_{2} \mathrm{~S}$ anyway, so it follows that inhibiting CSE with PPG has little effect.

Interestingly, the NaHS treatment reversed the inhibitory effect of Ang II infusion on vascular $\mathrm{H}_{2} \mathrm{~S}$ production, as L-cysteine-induced vasorelaxation was maintained in the Ang II infusion with the NaHS treatment. This suggests that the activity of CSE is sensitive to increased oxidative stress. To our knowledge, it has not been reported previously that NaHS can protect L-cysteine bioavailability, but this is a possibility. The data we present indeed indicate that NaHS treatment in vivo can protect CSE activity in the vasculature from Ang II infusion; however, we did not measure CSE protein levels or conduct other CSE activity assays to further investigate this. It is also possible that other sources of $\mathrm{H}_{2} \mathrm{~S}$ are upregulated under conditions of CSE inhibition. It is reported that 3-mercaptopyruvate sulfurtransferase and cysteine aminotransferase can also produce $\mathrm{H}_{2} \mathrm{~S}$ in vascular cells, ${ }^{9}$ although the regulation of this enzyme is not well understood, especially not in vivo. $\mathrm{H}_{2} \mathrm{~S}$ can also be produced by CBS, although this enzyme is generally associated with the neural production. ${ }^{65}$ Further potential sources of $\mathrm{H}_{2} \mathrm{~S}$ are from bound or acid-labile sulfur storage sites in mitochondria ${ }^{66}$ and other nonenzymatic sources, although the physiological relevance of these is yet to be determined. A more perplexing finding is that NaHS treatment restored CSE activity, as observed with both the vasorelaxation responses to L-cysteine and via aortic $\mathrm{H}_{2} \mathrm{~S}$ production. The reason for this is unclear, but suggests that $\mathrm{H}_{2} \mathrm{~S}$ may regulate CSE activity.

More work is still required though to examine the pharmacokinetics of NaHS. The $t_{1 / 2}$ and the fate of the administered NaHS are not well understood, and it is noted that the present results are obtained from a single daily i.p. dose of NaHS for a relatively short period. The dose of NaHS used is appropriate as it has returned $\mathrm{H}_{2} \mathrm{~S}$ production back to control levels, thus compensating for the decrease in endogenous $\mathrm{H}_{2} \mathrm{~S}$ that is observed with chronic AngII infusion. $\mathrm{H}_{2} \mathrm{~S}$ may react with methemoglobin to form sulfhemoglobin that acts as a sink for $\mathrm{H}_{2} \mathrm{~S}$, which subsequently releases $\mathrm{H}_{2} \mathrm{~S}$ upon reduction. Another possibility for this effect is that $\mathrm{H}_{2} \mathrm{~S}$ may signal through protein sulfhydration; ${ }^{67}$ thus, it is possible that NaHS treatment has a longer lasting effect. The field is plagued with a lack of tools, in particular selective and specific blockers of $\mathrm{H}_{2} \mathrm{~S}$ producing enzymes and reliable scavengers although consistent and stable donors of $\mathrm{H}_{2} \mathrm{~S}$ are now becoming available. Improvements in these will be most useful for advances in the study of $\mathrm{H}_{2} \mathrm{~S}$ biology.

\section{CONCLUSIONS}

These data show that in a mouse model of oxidative stress induced by AngII, exogenous $\mathrm{H}_{2} \mathrm{~S}$ treatment in vivo reduces blood pressure, vascular oxidative stress, endothelial damage and protects $\mathrm{NO}$ bioavailability. Inhibiting endogenous $\mathrm{H}_{2} \mathrm{~S}$ production in vivo exacerbated vascular superoxide formation. These data provide evidence that $\mathrm{H}_{2} \mathrm{~S}$ is a vasoprotective molecule that may be a useful treatment target in cardiovascular disease.

\section{ACKNOWLEDGEMENTS}

We wish to thank Jeffrey Moore (Monash University) for assistance with surgical procedures, They Ng (RMIT University) for assistance with biochemical assays and the RMIT animal facility staff. Grants from Ramaciotti Foundation, William Buckland Foundation and the School of Medical Sciences, RMIT University helped fund this work. MA was the recipient of a scholarship from the Hashemite University, Jordan.

1 Wang R. Two's company, three's a crowd: can $\mathrm{H}_{2} \mathrm{~S}$ be the third endogenous gaseous transmitter? FASEB J 2002; 16: 1792-1798.

2 Hart JL. Role of sulfur-containing gaseous substances in the cardiovascular system. Front Biosci (Elite Ed) 2011; 3: 736-749.

3 Streeter $\mathrm{E}, \mathrm{Ng} \mathrm{HH}$, Hart JL. Hydrogen sulfide as a vasculoprotective factor. Med Gas Res 2013; 3: 9.

4 Yang G, Wu L, Jiang B, Yang W, Qi J, Cao K, Meng Q, Mustafa AK, Mu W, Zhang S Snyder $\mathrm{SH}$, Wang R. $\mathrm{H}_{2} \mathrm{~S}$ as a physiologic vasorelaxant: hypertension in mice with deletion of cystathionine gamma-lyase. Science 2008; 322: 587-590.

5 Zhao W, Zhang J, Lu Y, Wang R. The vasorelaxant effect of $\mathrm{H}_{2} \mathrm{~S}$ as a novel endogenous gaseous $\mathrm{K}_{\text {ATP }}$ channel opener. EMBO J 2001; 20: 6008-6016. 
6 Webb GD, Lim LH, Oh VM, Yeo SB, Cheong YP, Ali MY, El Oakley R, Lee CN, Wong PS, Caleb MG, Salto-Tellez M, Bhatia M, Chan ES, Taylor EA, Moore PK. Contractile and vasorelaxant effects of hydrogen sulfide and its biosynthesis in the human internal mammary artery. J Pharmacol Exp Ther 2008; 324: 876-882.

7 Al-Magableh MR, Hart JL. Mechanism of vasorelaxation and role of endogenous hydrogen sulfide production in mouse aorta. Naunyn Schmiedebergs Arch Pharmacol 2011; 383: 403-413.

8 Yan H, Du J, Tang C. The possible role of hydrogen sulfide on the pathogenesis of spontaneous hypertension in rats. Biochem Biophys Res Commun 2004; 313: 22-27.

9 Shibuya N, Mikami Y, Kimura Y, Nagahara N, Kimura H. Vascular endothelium expresses 3-mercaptopyruvate sulfurtransferase and produces hydrogen sulfide. J Biochem 2009; 146: 623-626.

10 Carballal S, Trujillo M, Cuevasanta E, Bartesaghi S, Moller MN, Folkes LK, GarciaBereguiain MA, Gutierrez-Merino C, Wardman P, Denicola A, Radi R, Alvarez B. Reactivity of hydrogen sulfide with peroxynitrite and other oxidants of biological interest. Free Radic Biol Med 2010; 50: 196-205.

11 Stasko A, Brezova V, Zalibera M, Biskupic S, Ondrias K. Electron transfer: a primary step in the reactions of sodium hydrosulphide, an $\mathrm{H}_{2} \mathrm{~S} / \mathrm{HS}^{-}$donor. Free Radic Res 2009; 43: 581-593.

12 Whiteman M, Armstong J, Chu S, Jia-Ling S, Wong B, Cheung N, Halliwell B, Moore P. The novel neuromodulator hydrogen sulfide: an endogenous peroxynitrite 'scavenger'? J Neurochem 2004; 90: 765-768.

13 Filipovic MR, Miljkovic J, Allgauer A, Chaurio R, Shubina T, Herrmann M, Ivanovic-Burmazovic I. Biochemical insight into physiological effects of $\mathrm{H}_{2} \mathrm{~S}$ : reaction with peroxynitrite and formation of a new nitric oxide donor, sulfinyl nitrite. Biochem $J$ 2012; 441: 609-621.

$14 \mathrm{Lu} \mathrm{M}, \mathrm{Hu}$ LF, Hu G, Bian JS. Hydrogen sulfide protects astrocytes against $\mathrm{H}_{2} \mathrm{O}_{2}$-induced neural injury via enhancing glutamate uptake. Free Radic Biol Med 2008; 45: 1705-1713.

15 Whiteman M, Cheung N, Zhu Y, Chu S, Siau J, Wong B, Armstrong J, Moore P. Hydrogen sulphide: a novel inhibitor of hypochlorous acid-mediated oxidative damage in the brain? Biochem Biophys Res Commun 2005; 343: 303-310.

16 Al-Magableh MR, Kemp-Harper BK, Ng HH, Miller AA, Hart JL. Hydrogen sulfide protects endothelial nitric oxide function under conditions of acute oxidative stress in vitro. Naunyn Schmiedebergs Arch Pharmacol 2014; 387: 67-74.

17 Kimura Y, Goto Y, Kimura H. Hydrogen sulfide increases glutathione production and suppresses oxidative stress in mitochondria. Antioxid Redox Signal 2010; 12 : $1-13$

18 Schulz E, Gori T, Munzel T. Oxidative stress and endothelial dysfunction in hypertension. Hypertens Res. 2011; 34: 665-673.

19 Chen AF, Chen DD, Daiber A, Faraci FM, Li H, Rembold CM, Laher I. Free radical biology of the cardiovascular system. Clin Sci (Lond) 2012; 123: 73-91.

20 Drummond GR, Selemidis S, Griendling KK, Sobey CG. Combating oxidative stress in vascular disease: NADPH oxidases as therapeutic targets. Nat Rev Drug Discov 2011; 10: 453-471.

21 Cai $\mathrm{H}$, Griendling KK, Harrison DG. The vascular NAD(P)H oxidases as therapeutic targets in cardiovascular diseases. Trends Pharmacol Sci 2003; 24: 471-478.

$22 \mathrm{Cai}$ H. NAD(P)H oxidase-dependent self-propagation of hydrogen peroxide and vascular disease. Circ Res 2005; 96: 818-822.

23 Widder JD, Fraccarollo D, Galuppo P, Hansen JM, Jones DP, Ertl G, Bauersachs J. Attenuation of angiotensin II-induced vascular dysfunction and hypertension by overexpression of Thioredoxin 2. Hypertension 2009; 54: 338-344.

24 Stipanuk MH, Beck PW. Characterization of the enzymic capacity for cysteine desulphhydration in liver and kidney of the rat. Biochem J 1982; 206: 267-277.

25 Predmore BL, Lefer DJ, Gojon G. Hydrogen sulfide in biochemistry and medicine. Antioxid Redox Signal 2012; 17: 119-140.

26 Lefer DJ. A new gaseous signalling molecule emerges: cardioprotective role of hydrogen sulphide. PNAS 2007; 104: 2.

27 Kimura Y, Kimura $\mathrm{H}$. Hydrogen sulfide protects neurons from oxidative stress. FASEB J 2004; 18: 1165-1167.

28 Calvert JW, Coetzee WA, Lefer DJ. Novel insights into hydrogen sulfide-mediated cytoprotection. Antioxid Redox Signal12: 1203-1217.

29 Zhao W, Wang R. $\mathrm{H}_{2} \mathrm{~S}$-induced vasorelaxation and underlying cellular and molecular mechanisms. Am J Physiol Heart Circ Physiol 2002; 283: H474-H480.

30 Cheng Y, Ndisang J, Tang G, Cao K, Wang R. Hydrogen sulfide-induced relaxation of resistance mesenteric artery beds of rats. Am J Physiol Heart Circ Physiol 2004; 287: 2316-2323.

31 Sun Y, Tang CS, Du JB, Jin HF. Hydrogen sulfide and vascular relaxation. Chin Med J (Engl) 2011; 124: 3816-3819.

32 Streeter E, Hart J, Badoer E. An investigation of the mechanisms of hydrogen sulfideinduced vasorelaxation in rat middle cerebral arteries. Naunyn Schmiedebergs Arch Pharmacol 2012; 385: 991-1002.

33 Bucci M, Papapetropoulos A, Vellecco V, Zhou Z, Pyriochou A, Roussos C, Roviezzo F, Brancaleone V, Cirino G. Hydrogen sulfide is an endogenous inhibitor of phosphodiesterase activity. Arterioscler Thromb Vasc Biol 2010; 30: 1998-2004.

34 Bucci M, Papapetropoulos A, Vellecco V, Zhou Z, Zaid A, Giannogonas P, Cantalupo A Dhayade S, Karalis KP, Wang R, Feil R, Cirino G. cGMP-dependent protein kinase contributes to hydrogen sulfide-stimulated vasorelaxation. PLOS ONE 2012; 7: e53319.

35 Li L, Whiteman M, Guan YY, Neo KL, Cheng Y, Lee SW, Zhao Y, Baskar R, Tan CH, Moore PK. Characterization of a novel, water-soluble hydrogen sulfide-releasing molecule (GYY4137): new insights into the biology of hydrogen sulfide. Circulation 2008; 117: 2351-2360.
36 Chrissobolis S, Faraci FM. The role of oxidative stress and NADPH oxidase in cerebrovascular disease. Trends Mol Med 2008; 14: 495-502.

37 Chang RS, Lotti VJ, Keegan ME. Inactivation of angiotensin II receptors in bovine adrenal cortex by dithiothreitol: further evidence for the essential nature of disulfide bonds. Biochem Pharmacol 1982; 31: 1903-1906.

38 Ullian ME, Gelasco AK, Fitzgibbon WR, Beck CN, Morinelli TA. N-acetylcysteine decreases angiotensin II receptor binding in vascular smooth muscle cells. J Am Soc Nephrol 2005; 16: 2346-2353.

39 Zhang JS, van Meel JC, Pfaffendorf M, van Zwieten PA. Inhibitory effect of dithiothreitol on angiotensin II-induced contractions mediated by AT1-receptors in rat portal vein and rabbit aorta. Naunyn Schmiedebergs Arch Pharmacol 1994; 349: 538-542.

40 Heerding JN, Hines J, Fluharty SJ, Yee DK. Identification and function of disulfide bridges in the extracellular domains of the angiotensin II type 2 receptor. Biochemistry 2001 ; 40: 8369-8377.

41 Zhao X, Zhang LK, Zhang CY, Zeng XJ, Yan H, Jin HF, Tang CS, Du JB. Regulatory effect of hydrogen sulfide on vascular collagen content in spontaneously hypertensive rats. Hypertens Res 2008; 31: 1619-1630.

42 Jones ES, Vinh A, McCarthy CA, Gaspari TA, Widdop RE. AT2 receptors: functional relevance in cardiovascular disease. Pharmacol Ther 2008; 120: 292-316.

43 Muzaffar S, Shukla N, Bond M, Newby AC, Angelini GD, Sparatore A, Del Soldato P, Jeremy JY. Exogenous hydrogen sulfide inhibits superoxide formation, NOX-1 expression and Rac1 activity in human vascular smooth muscle cells. J Vasc Res 2008; 45: 521-528.

44 Muzaffar S, Jeremy JY, Sparatore A, Del Soldato P, Angelini GD, Shukla N. $\mathrm{H}_{2} \mathrm{~S}$-donating sildenafil (ACS6) inhibits superoxide formation and gp91phox expression in arterial endothelial cells: role of protein kinases A and G. Br J Pharmacol 2008; 155: 984-994.

45 Ford A, AI-Magableh M, Gaspari TA, Hart JL. Chronic NaHS treatment is vasoprotective in high fat fed ApoE ${ }^{-1-}$ mice. Int J Vasc Med 2013; 2013: 915983.

46 Mitsuhashi H, Yamashita S, Ikeuchi H, Kuroiwa T, Kaneko Y, Hiromura K, Ueki K, Nojima Y. Oxidative stress-dependent conversion of hydrogen sulfide to sulfite by activated neutrophils. Shock 2005; 24: 529-534

47 Streeter EY, Badoer E, Woodman OL, Hart JL. Effect of type 1 diabetes on the production and vasoactivity of hydrogen sulfide in rat middle cerebral arteries. Physiol Rep 2013; 1: e00111.

48 Gryglewski RJ, Palmer RM, Moncada S. Superoxide anion is involved in the breakdown of endothelium-derived vascular relaxing factor. Nature 1986; 320: 454-456.

49 MacKenzie A, Martin W. Loss of endothelium-derived nitric oxide in rabbit aorta by oxidant stress: restoration by superoxide dismutase mimetics. Br J Pharmacol 1998; 124: 719-728.

50 Pacher P, Beckman JS, Liaudet L. Nitric oxide and peroxynitrite in health and disease. Physiol Rev 2007; 87: 315-424.

51 Vasquez-Vivar J, Kalyanaraman B, Martasek P. The role of tetrahydrobiopterin in superoxide generation from eNOS: enzymology and physiological implications. Free Radic Res 2003; 37: 121-127.

52 Rodrigo R, Gonzalez J, Paoletto F. The role of oxidative stress in the pathophysiology of hypertension. Hypertens Res 2011; 34: 431-440.

53 Didion SP, Kinzenbaw DA, Faraci FM. Critical role for CuZn-superoxide dismutase in preventing angiotensin II-induced endothelial dysfunction. Hypertension 2005; 46: 1147-1153.

54 Chrissobolis S, Didion SP, Kinzenbaw DA, Schrader LI, Dayal S, Lentz SR, Faraci FM. Glutathione peroxidase-1 plays a major role in protecting against angiotensin II-induced vascular dysfunction. Hypertension 2008; 51: 872-877.

55 Leo $\mathrm{CH}$, Hart JL, Woodman OL. 3',4'-Dihydroxyflavonol reduces superoxide and improves nitric oxide function in diabetic rat mesenteric arteries. PLOS ONE 2011; 6: e20813.

56 Benetti LR, Campos D, Gurgueira SA, Vercesi AE, Guedes CE, Santos KL, Wallace JL, Teixeira SA, Florenzano J, Costa SK, Muscara MN, Ferreira HH. Hydrogen sulfide inhibits oxidative stress in lungs from allergic mice in vivo. Eur J Pharmacol 2012; 698: 463-469

57 Sun WH, Liu F, Chen Y, Zhu YC. Hydrogen sulfide decreases the levels of ROS by inhibiting mitochondrial complex IV and increasing SOD activities in cardiomyocytes under ischemia/reperfusion. Biochem Biophys Res Commun 2012; 421: 164-169.

58 Yan SK, Chang T, Wang H, Wu L, Wang R, Meng QH. Effects of hydrogen sulfide on homocysteine-induced oxidative stress in vascular smooth muscle cells. Biochem Biophys Res Commun 2006; 351: 485-491.

59 Altaany Z, Yang G, Wang R. Crosstalk between hydrogen sulfide and nitric oxide in endothelial cells. J Cell Mol Med 2013; 17: 879-888.

60 Kida M, Sugiyama T, Yoshimoto T, Ogawa Y. Hydrogen sulfide increases nitric oxide production with calcium-dependent activation of endothelial nitric oxide synthase in endothelial cells. Eur J Pharm Sci 2013; 48: 211-215.

61 Meng J, Ganesan Adaikan P, Srilatha B. Hydrogen sulfide promotes nitric oxide production in corpus cavernosum by enhancing expression of endothelial nitric oxide synthase. Int J Impot Res 2013; 23: 86-90.

62 Liu YH, Yan CD, Bian JS. Hydrogen sulfide: a novel signaling molecule in the vascular system. J Cardiovasc Pharmacol 2011; 58: 560-569.

63 Johnston M, Jankowski D, Marcotte P, Tanaka H, Esaki N, Soda K, Walsh C. Suicide inactivation of bacterial cystathionine gamma-synthase and methionine gamma-lyase during processing of L-propargylglycine. Biochemistry 1979; 18: 4690-4701.

64 Asimakopoulou A, Panopoulos P, Chasapis CT, Coletta C, Zhou Z, Cirino G, Giannis A, Szabo C, Spyroulias GA, Papapetropoulos A. Selectivity of 
commonly used pharmacological inhibitors for cystathionine beta synthase (CBS) and cystathionine gamma lyase (CSE). Br J Pharmacol 2013; 169 922-932.

65 Kimura H. Hydrogen sulfide: its production, release and functions. Amino Acids 2011 ; 41: $113-121$
66 Ishigami M, Hiraki K, Umemura K, Ogasawara Y, Ishii K, Kimura H. A source of hydrogen sulfide and a mechanism of its release in the brain. Antioxid Redox Signal 2009; 11: 205-214.

67 Mustafa AK, Gadalla MM, Sen N, Kim S, Mu W, Gazi SK, Barrow RK, Yang G, Wang R Snyder SH. $\mathrm{H}_{2} \mathrm{~S}$ signals through protein S-sulfhydration. Sci Signal 2009; 2: ra72. 